\title{
Implicações da interação genótipos $x$ ambientes sobre ganhos com a seleção em meloeiro
}

\author{
Implications of genotype $x$ environment interaction on the gain with melon selection
}

\author{
José Milton da Silva ${ }^{\mathrm{I}}$ Glauber Henrique de Sousa Nunes ${ }^{\mathrm{I}}$ Gabriel Guimarães Costa $^{\mathrm{I}^{*}}$ \\ Fernando Antônio de Souza Aragão ${ }^{\text {II }}$ Lívia Karla Remígio Maia
}

\section{RESUMO}

\begin{abstract}
O objetivo do presente trabalho foi estudar o efeito da interação genótipos por ambientes sobre a avaliação de famílias de meloeiro. Foram avaliadas 144 famílias na geração $S_{6}$ em quatro municípios, Mossoró, Baraúna, Assu e Alto do Rodrigues, em um látice simples 12x12. As características avaliadas foram: produtividade, peso médio do fruto, proporção da cavidade interna, espessura da polpa, firmeza da polpa e teor de sólidos solúveis. Constatou-se efeito significativo de famílias nos quatro ambientes de avaliação $e$ na análise conjunta para todas as características. A interação familias $x$ locais foi acentuada, sendo a estimativa do componente de variância da interação superior àquele da variância genética entre famílias. Ocorreu superioridade na contribuição da parte complexa em relação à simples da interação para todas as características. A interação famílias $x$ ambientes teve reflexo na seleção, pois a resposta correlacionada pela seleção em um ambiente e ganho em outro sempre foi inferior ao ganho da seleção direta. As estimativas de coeficiente de variação genética e variância genética entre familias foram superestimadas pelo componente da interação famílias $x$ locais, sendo necessárias avaliações em ambientes diferentes. A seleção com base no comportamento médio das famílias foi eficiente, pois proporcionou maiores ganhos de seleção do que aqueles obtidos com base na seleção no ambiente individual.
\end{abstract}

Palavras-chave: Cucumis melo, ganho genético, seleção, adaptabilidade.

\section{ABSTRACT}

The objective of this research was to study the genotype $x$ environment effect on the selection of melon families. It was evaluated 144 melon families at four sites of Rio Grande do Norte State, Brazil. The experiments were carried out in a design of simple lattice $12 \times 12$ in Mossoró, Barauna, Assu and Alto do Rodrigues sites. The traits assessing were yield, average of weight fruit, intern cavity proportion, pulp thickness, pulp firmness and content solids soluble. It was observed effect of families in all sites and the join analysis for all traits. The family $x$ site interaction was high and the estimation of the interaction variance component was higher than the genetic variance among families. The complex interaction was higher than the simple one. The family $x$ site interaction reflected in the selection, as the correlated response to selection in one environment observed in another was always lower than the gain of direct selection. The estimates of the genetic variation coefficient and genetic variance were overestimated by family $x$ site interaction, consequently, the evaluation should be carried out in different sites. The selection based on the mean over sites was effectiveness because the genetic expected that gains were more expressive than gains based in the individual environment.

Key words: Cucumis melo, genetic expected gain, selection, adaptability.

\section{INTRODUÇÃO}

A maioria dos frutos de melões produzidos no Agropolo Mossoró-Assu pertence ao grupo inodorus, o qual contempla os tipos Amarelo, Pele de sapo e Honey Dew. Não obstante, com a intenção de diversificar o produto oferecido, muitas empresas têm cultivado o tipo Gália, correspondendo a aproximadamente $11 \%$ do melão exportado no porto de Natal. A intenção dos produtores é aumentar a área

'Departamento de Ciências Vegetais, Universidade Federal Rural do Semi-Árido (UFERSA), Km 47, BR 110, Costa e Silva, CP 137, 59625-900, Mossoró, RN, Brasil. E-mail: gabrieljua@yahoo.com.br.*Autor para correspondência.

"Embrapa Agroindústria Tropical, Fortaleza, CE, Brasil. 
plantada com esse tipo de melão, em razão da sua alta cotação no mercado externo (SALES JÚNIOR et al., 2006).

O melão Gália foi desenvolvido em meados da década de sessenta, sendo o primeiro híbrido simples desenvolvido por programa de melhoramento realizado em Israel. É resultante do cruzamento de uma linhagem de melão Ogen e outra de melão Honey Dew. Seus frutos são esféricos, aromáticos, peso entre 1 a $1,5 \mathrm{~kg}$, polpa esverdeada e teor de sólidos solúveis entre $13 \mathrm{e}$ $15 \%$ (KARCHI, 2000).

Ainda é pequeno o número de híbridos de melão Gália disponíveis para os produtores do Rio Grande do Norte. Entre os mais cultivados, estão o Galileu e o Solarking, embora a área de cultivo com esses genótipos tenha decrescido acentuadamente nos últimos anos em razão de problemas fitossanitários e de pós-colheita. Existem poucos trabalhos de avaliação de cultivares de melão Gália no Estado potiguar. SANTOS JÚNIOR (2002), avaliando em Mossoró seis híbridos simples de melão Gália, observou que os híbridos DRG 1531 e DRG 1537 foram os mais promissores.

No programa de melhoramento genético desenvolvido na Universidade Federal Rural do SemiÁrido (UFERSA) foram obtidas famílias de melão Gália por autofecundações do cruzamento entre os híbridos DRG 1537 e AMR-04. Nesse sentido, são necessários estudos de avaliação das famílias para selecionar as mais promissoras para etapas subsequentes do trabalho desenvolvido por esta instituição, visando o desenvolvimento de híbridos simples.

Por outro lado, considerando que no Agropolo Mossoró-Assu há diversidade edafoclimática, espera-se a ocorrência da interação genótipos por ambientes e que esta tenha um papel relevante no fenótipo. Estudos com o meloeiro têm mostrado a presença da interação em experimentos de avaliação de cultivares (GURGEL et al., 2005; NUNES et al., 2006; FREITAS et al., 2007). Assim sendo, aconselha-se a avaliação em mais de um local para que o efeito da interação possa ser estimado e atenuado. Não há registros do efeito da interação genótipos por ambientes sobre as estimativas de componentes de variância, obtidas em avaliações de populações segregantes de meloeiro, bem como seu efeito sobre os ganhos com a seleção. Portanto, é necessário obter informações que possam orientar os melhoristas dessa cucurbitácea e possibilitar estimativas de parâmetros genéticos mais fidedignas.

O objetivo do presente trabalho foi estudar o efeito da interação genótipos por ambientes sobre a avaliação de famílias de meloeiro.

\section{MATERIAL E MÉTODOS}

Os locais de avaliação foram: Mossoró $\left(5^{\circ} 11^{\prime} \mathrm{S}\right.$ e $37^{\circ} 21^{\prime} \mathrm{W}, 18 \mathrm{~m}$ de altitude, temperatura média $29,5^{\circ} \mathrm{C}$, umidade relativa $47,51 \%$, precipitação $2,77 \mathrm{~mm}$ e solo Argissolo Vermelho-Amarelo Equivalente Eutrófico); Baraúna $\left(5^{\circ} 05^{\prime} \mathrm{S}\right.$ e $37^{\circ} 38^{\prime} \mathrm{W}, 95 \mathrm{~m}$ de altitude, temperatura média $27,34^{\circ} \mathrm{C}$, umidade relativa $45,58 \%$, precipitação 2,67mm e solo Cambissolo Háplico); Assu ( $5^{\circ} 34^{\prime} \mathrm{S}$ e $36^{\circ} 54^{\prime} \mathrm{W}, 27$ metros de altitude, temperatura média $27,20^{\circ} \mathrm{C}$, umidade relativa $53,99 \%$, precipitação $12,67 \mathrm{~mm}$ e solo Neossolo Aluvional); e Alto do Rodrigues $\left(5^{\circ} 21^{\prime} \mathrm{S}\right.$ e $36^{\circ} 53^{\prime} \mathrm{W}, 29$ metros de altitude, temperatura média de $28,36^{\circ} \mathrm{C}$, umidade relativa $52,31 \%$, precipitação $4,37 \mathrm{~mm}$ e solo Cambissolo Eutrófico). Todos os experimentos foram conduzidos durante $\mathrm{o}$ período de junho a agosto de 2006.

Foram utilizados os híbridos simples DRG1537 e AMR-04 para geração das famílias. Ambos são híbridos simples e com expressão sexual andromonóica. O híbrido DRG-1537 é do tipo Gália, possui frutos redondos, com peso médio em torno de $1,5 \mathrm{~kg}$, resistência à raça 1 do fungo Podosphaera xanthii, resistência à raça 1 do fungo Fusarium oxisporum, polpa branca e não aromática e elevado teor de sólidos solúveis totais (12-13\%). O híbrido AM-04 é do tipo Amarelo, possui resistência ao fungo de solo Myrothecium roridum, resistência à raça 1 do fungo P. xanthii, resistência à raça 1 do fungo $\boldsymbol{F}$. oxisporum, com fruto redondo, peso médio de $1,7 \mathrm{~kg}$, casca amarela, rugosa, polpa branca, firme e elevado teor de sólidos solúveis totais (12 a 14\%).

Realizou-se o cruzamento entre os híbridos DRG-1537 e AMR-04 em campo. As sementes foram colhidas, misturadas e armazenadas em câmara fria e seca por três meses. Essas sementes originaram uma população de 380 plantas, nas quais foram realizadas autofecundações em campo. $\mathrm{O}$ avanço das gerações de autofecundação foi realizado pelo método descendente de uma semente ou SSD (Single Seed Descendent). Foram realizadas cinco gerações de autofecundações, quando as famílias se encontravam na geração $\mathrm{S}$, realizou-se a seleção em blocos aumentados para características de qualidade do fruto, precocidade e produtividade, deixando-se 144 famílias.

Em todos os ambientes, o cultivo foi conduzido sob irrigação por gotejamento, com fertirrigação, com o volume de água em torno de $300 \mathrm{~m}^{3}$ $\mathrm{ha}^{-1}$. Os fertilizantes foram aplicados de acordo com as recomendações baseadas na análise do solo. As demais práticas culturais foram realizadas conforme a recomendação de manejo para a cultura no estado (NUNES et al., 2004). 
O experimento foi realizado em delineamento em látice simples $12 \times 12$. Cada parcela foi constituída por duas linhas de $5,0 \mathrm{~m}$ de comprimento, espaçadas por $2,0 \mathrm{~m}$, o espaçamento entre plantas foi $0,5 \mathrm{~m}$, sendo plantada uma planta por cova. Cada parcela possuía 20 plantas. As plantas das extremidades das duas linhas da parcela formaram a bordadura de cabeceira, sendo a área útil composta por 16 plantas centrais.

As características avaliadas foram produtividade, peso médio do fruto, espessura de polpa, proporção da cavidade interna, firmeza da polpa e sólidos solúveis, conforme descrito por NUNES et al. (2005). Para as medições da espessura da polpa, proporção da cavidade interna, firmeza da polpa e teor de sólidos solúveis foram amostrados dez frutos por parcela.

Foram realizadas as análises de variância por local e posteriormente a análise conjunta, envolvendo os quatro locais, após a comprovação da homogeneidade de variâncias residuais pelo teste de Bartlett. Foram estimadas as variâncias genéticas entre famílias $\left(\sigma_{\mathrm{F}}^{2}\right)$ (individual e conjunta), a variância da interação famílias $\mathrm{x}$ ambientes $\left(\sigma_{\mathrm{FL}}^{2}\right)$ na análise conjunta e a herdabilidade $\left(\mathrm{h}^{2}\right)$, conforme descrito CRUZ et al. (2004). Para decompor a interação famílias por ambientes nas partes simples e complexa foram realizadas análises de variâncias com os locais dois a dois. Foi utilizada a metodologia proposta por CRUZ \& CASTOLDI (1991).
O ganho obtido pela seleção direta praticada em cada ambiente, o ganho obtido com a resposta indireta à seleção realizada nos quatro ambientes de avaliação e o ganho obtido com a resposta indireta à seleção realizada na média dos quatro ambientes de avaliação foram estimados conforme descrito por CRUZ et al. (2004), sendo empregada uma intensidade de seleção de $25 \%$. Todas as análises foram procedidas com o auxílio do programa computacional GENES (CRUZ, 2008).

\section{RESULTADOS E DISCUSSÃO}

Em experimentos de avaliação de genótipos em programa de melhoramento genético, é imprescindível ter elevada precisão para que as diferenças entre os materiais avaliados possam ser detectadas. O coeficiente de variação (CV) é a medida mais utilizada para se comparar a precisão experimental. No presente trabalho, as estimativas dos CV's estão dentro da faixa observada para a cultura em outros trabalhos de avaliação de cultivares (NUNES et al., 2004; NUNES et al., 2005). Os valores verificados podem ser classificados como médios, conforme a classificação estabelecida por LIMA et al. (2004) para o meloeiro (Tabela 1).

O delineamento em látice foi eficiente para todas as características (Tabela 1). A maior eficiência do látice em relação ao delineamento de blocos

Tabela 1 - Resumo das análises de variância conjunta de seis características de famílias de meloeiro avaliadas na geração $\mathrm{S}_{6}$ em quatro municípios do Rio Grande do Norte. Mossoró-RN, 2006.

\begin{tabular}{|c|c|c|c|c|c|c|c|}
\hline \multirow{2}{*}{ FV } & \multirow{2}{*}{ gl } & \multicolumn{6}{|c|}{ 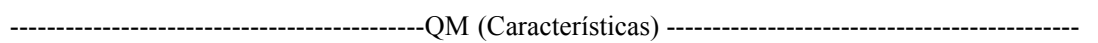 } \\
\hline & & PROD & PMF & PCI & EP & FP & SS \\
\hline Famílias (F) & 143 & $25,92^{* *}$ & $73975,58^{* *}$ & $82,16^{* *}$ & $0,21^{* *}$ & $26,28^{* *}$ & $6,18^{* *}$ \\
\hline Locais (L) & 3 & $1728,13^{* *}$ & $970394,62^{* *}$ & $1388,24^{* *}$ & $73,30^{* *}$ & $160,08^{* *}$ & $177,27^{* *}$ \\
\hline$F \times L$ & 429 & $27,83^{* *}$ & $79448,33^{* *}$ & $66,80^{* *}$ & $0,18^{* *}$ & $23,89^{* *}$ & $5,58^{* *}$ \\
\hline Erro médio & 484 & 14,98 & 5615,6 & 52,7 & 0,12 & 12,27 & 2,58 \\
\hline Média & & 22,22 & 1604,84 & 55,94 & 3,26 & 26,88 & 13,02 \\
\hline $\mathrm{CV}_{\mathrm{E}}(\%)$ & & 17,42 & 14,16 & 12,97 & 10,44 & 13,04 & 12,32 \\
\hline EL & & 112,25 & 124,86 & 134,52 & 129,15 & 130,25 & 127,23 \\
\hline $\mathrm{S}(\%)$ & & 3,75 & 2,69 & 3,24 & 9,84 & 3,84 & 3,22 \\
\hline $\mathrm{C}(\%)$ & & 96,25 & 97,31 & 97,76 & 90,16 & 96,16 & 96,78 \\
\hline$\hat{\sigma}_{F L}^{2}$ & & 4,81 & 10435,80 & 5,28 & 0,02 & 4,35 & 1,12 \\
\hline$\hat{\sigma}_{F}^{2} / \hat{\sigma}_{F L}^{2}$ & & 0,28 & 0,26 & 0,69 & 0,40 & 0,50 & 0,40 \\
\hline
\end{tabular}

PROD: produtividade $\left(\mathrm{t} \mathrm{ha}^{-1}\right)$; PMF: peso médio do fruto (g); PCI: proporção da cavidade interna (\%); EP: espessura da polpa (cm); FP: firmeza da polpa $(\mathrm{N})$; SS: sólidos solúveis (\%); EL: eficiência do látice; $\mathrm{S}(\%)$ e $\mathrm{C}(\%)$ : partes simples e complexa da interação, respectivamente; $\sigma_{\mathrm{F}}^{2}$ : variância genética entre famílias; $\sigma_{\mathrm{FL}}^{2}$ : variância da interação famílias $\mathrm{x}$ ambientes; **: significativo a $1 \%$ de probabilidade pelo teste F de Snedecor. 
casualizados ocorre quando a variação dentro dos blocos nas repetições é menor do que a variação entre repetições. Esse resultado era esperado em razão da grande área que constituiu o experimento, uma vez que quanto maior a área experimental, maior é a chance de ocorrer heterogeneidade do solo.

$\mathrm{Na}$ análise conjunta, os efeitos de local, de família e da interação entre esses fatores foram significativos para todas as características. Esse resultado indica heterogeneidade genética entre famílias. A distinção do efeito de locais se deveu, provavelmente, às diferenças no tipo de solo e do manejo da cultura em cada local. Em razão disso, era esperado efeito pronunciado do ambiente, como foi verificado neste trabalho. A presença da interação genótipos por ambientes indica comportamento diferenciado das famílias nos ambientes de avaliação. A interação genótipos por ambiente em melão tem sido verificada em estudos de avaliação de híbridos de melão amarelo (GURGEL et al., 2005; NUNES et al., 2006; FREITAS et al., 2007) e melão Gália (SANTOS JÚNIOR, 2002). A presença da interação genótipos por ambientes tem um papel fundamental na manifestação fenotípica e pode influenciar muito o processo de seleção de cultivares ou de famílias. A consequência prática para o melhorista é a dificuldade no processo de seleção de genótipos promissores.

A razão entre o componente de variância da genética entre as famílias $\left(\sigma^{2} \mathrm{~F}\right)$ e a variância da interação $\left(\sigma^{2} \mathrm{FL}\right)$ foi sempre inferior à unidade para todas as características (Tabela 1). Quanto menor o valor da razão $\sigma^{2} \mathrm{~F} / \sigma^{2} \mathrm{FL}$, maior é a contribuição do componente da interação genótipos por ambientes para manifestação fenotípica. Com efeito, a ocorrência pronunciada da interação evidencia a necessidade de avaliação dos genótipos em vários ambientes para que se tenha maior segurança na recomendação dos melhores.

Dois fatores compõem a interação genótipos por ambientes. O primeiro, denominado de parte simples, é devido às magnitudes das diferenças de variabilidade entre os genótipos e o segundo, denominado de parte complexa, depende da correlação genética dos genótipos nos ambientes (CRUZ \& CASTOLDI, 1991). No presente trabalho, verificou-se predomínio quase que absoluto da parte complexa da interação para todas as características (Tabela 1). NUNES et al. (2006) verificaram predomínio da parte complexa da interação para a produtividade e o teor de sólidos solúveis de híbridos experimentais de melão Amarelo, avaliados em doze ambientes do Agropolo Mossoró-Assu.

A quantificação dos fatores que compõem a interação é importante, porque informa ao melhorista sobre o grau de dificuldade no momento da seleção ou recomendação de cultivares. Quando há predomínio da parte simples, o trabalho do pesquisador é facilitado, pois a classificação genotípica não se altera. Por outro lado, quando a parte complexa é mais expressiva, torna a decisão mais difícil, uma vez que, nesse caso, existem genótipos que são bem adaptados a ambientes específicos (CRUZ et al., 2004). A interação genótipos $\mathrm{x}$ ambientes pode ser explorada pelo melhorista pela seleção de determinados genótipos para determinado ambiente ou região. Nesse caso, a interação é capitalizada, aumentando o valor fenotípico do caráter (NUNES et al., 2002).

Uma das implicações do efeito da interação pode ser observada nas estimativas de componentes de variância. Isso porque, em avaliações em apenas um local ou ambiente, a estimativa da variância genética fica superestimada pelo componente da interação genótipos por ambientes que não pode ser estimado. Por outro lado, em avaliações em mais de um ambiente, o componente da interação pode ser estimado e separado do efeito genético. No presente trabalho, foi contundente a superestimação das estimativas dos componentes de variância genética entre famílias (Tabela 2). Foram verificadas diferenças entre as estimativas da variância genética das análises individual e conjunta. A interação genótipos por ambientes, obviamente, também influencia a estimativa da herdabilidade (FALCONER \& MACKAY, 1996). Não obstante, a sua ação na superestimação das estimativas dos locais de avaliação nem sempre ocorreu neste trabalho (Tabela 2).

A interação influencia diretamente os ganhos com a seleção, devido à falta de correlação existente entre as médias dos genótipos nos ambientes de avaliação (FERREIRA et al., 2006). Assim sendo, quando a seleção é feita em um ambiente e a resposta é observada em outro, o ganho esperado com a seleção, na presença de uma forte interação, é reduzido. Na tabela 3 , estão os ganhos diretos com a seleção, ou seja, quando a seleção é praticada em um ambiente e a resposta é observada nesse mesmo ambiente, bem como os ganhos indiretos, quando a seleção é praticada em um ambiente e a resposta verificada em outro. Observou-se que os ganhos diretos foram sempre superiores aos ganhos indiretos, em todos as situações e para todas as características. Esse resultado reforça a presença acentuada da interação genótipos por ambientes. Vale ressaltar que em algumas situações os ganhos foram negativos. A presença de ganhos negativos indica correlação negativa entre as médias das famílias entre dois ambientes. Em outras palavras, pode-se dizer que a covariância genética entre as médias de famílias nos dois ambientes é negativa. Isso significa 
Tabela 2 - Estimativas de parâmetros genéticos das análises individual e conjunta de quatro municípios do Rio Grande do Norte para seis características de famílias de meloeiro. Mossoró-RN, 2006.

\begin{tabular}{llcccccc}
\hline \multirow{2}{*}{ Parâmetro } & Local & \multicolumn{3}{c}{ Estimativas (Características) } \\
& & PROD & PMF & PCI & EP & FP & SS \\
\hline \multirow{3}{*}{$\hat{\sigma}_{F}^{2}$} & Mossoró & 5,31 & 17214,20 & 12,98 & 0,01 & 4,44 & 1,07 \\
& Baraúna & 5,08 & 5438,70 & 8,24 & 0,04 & 6,81 & 1,81 \\
& Assu & 6,57 & 22163,71 & 7,58 & 0,06 & 4,10 & 1,83 \\
& Alto R. & 7,78 & 8104,54 & 7,07 & 0,02 & 9,07 & 1,56 \\
$\hat{h^{2}}$ & Conjunta & 1,37 & 2794,50 & 3,68 & 0,01 & 1,74 & 0,45 \\
& Mossoró & 49,83 & 37,32 & 34,01 & 30,61 & 47,05 & 45,22 \\
& Baraúna & 44,75 & 19,14 & 22,12 & 35,21 & 50,52 & 56,24 \\
& Assu & 42,40 & 44,82 & 24,37 & 35,36 & 46,73 & 66,75 \\
& Alto R. & 45,23 & 25,19 & 20,35 & 31,54 & 52,36 & 50,94 \\
& Conjunta & 42,20 & 30,22 & 35,85 & 43,84 & 53,24 & 58,35 \\
\hline
\end{tabular}

PROD: produtividade $\left(\mathrm{t} \mathrm{ha}^{-1}\right)$; PMF: peso médio do fruto (g); PCI: proporção da cavidade interna (\%); EP: espessura da polpa (cm); FP: firmeza da polpa (N); SS: sólidos solúveis (\%). ${\hat{\sigma_{F}}}^{2}$ : variância genética entre famílias. $\hat{h}^{2}$ : herdabilidade (\%).

que não há coincidência entre as melhores famílias nos dois locais de avaliação.

Ausência de ganhos indiretos ou ganhos negativos indicam que as famílias devem ser cultivadas apenas no local de seleção. Considerando que, no melhoramento genético, o principal objetivo é uma cultivar que possua um bom desempenho na maior parte da região de produção da hortaliça, os resultados constatados nesta pesquisa são desfavoráveis. Considerando que a região produtora de melão não

Tabela 3 - Ganhos diretos e indiretos com a seleção para seis características de famílias de meloeiro avaliadas em quatro municípios do Rio Grande do Norte. Mossoró-RN, 2006.

\begin{tabular}{|c|c|c|c|c|c|c|c|}
\hline \multirow{2}{*}{$A_{i}$} & \multirow{2}{*}{$\mathrm{A}_{\mathrm{j}}$} & \multicolumn{6}{|c|}{ 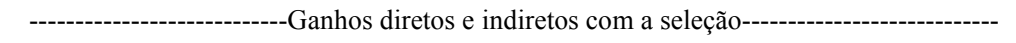 } \\
\hline & & PROD & PMF & PCI & EP & FP & SS \\
\hline Mossoró & Mossoró & 1,88 & 92,20 & 2,44 & 0,07 & 1,67 & 0,81 \\
\hline Mossoró & Baraúna & 0,36 & $-11,84$ & 1,74 & 0,00 & $-0,14$ & $-0,05$ \\
\hline Mossoró & Assu & $-0,59$ & 0,63 & 1,48 & $-0,02$ & $-0,04$ & 0,12 \\
\hline Mossoró & Alto R. & $-0,26$ & $-11,75$ & 0,61 & $-0,01$ & $-0,56$ & 0,03 \\
\hline Baraúna & Baraúna & 1,75 & 37,40 & 1,76 & 0,15 & 2,15 & 1,17 \\
\hline Baraúna & Mossoró & 0,35 & $-15,09$ & 1,56 & 0,00 & $-0,11$ & $-0,04$ \\
\hline Baraúna & Assu & $-0,17$ & $-1,10$ & 0,14 & 0,06 & $-0,23$ & $-0,10$ \\
\hline Baraúna & Alto R. & $-1,11$ & $-0,57$ & 0,00 & 0,00 & $-0,15$ & 0,31 \\
\hline Assu & Assu & 1,94 & 115,52 & 1,64 & 0,18 & 1,60 & 1,28 \\
\hline Assu & Mossoró & $-0,48$ & 0,61 & 1,58 & $-0,01$ & $-0,58$ & 0,11 \\
\hline Assu & Baraúna & $-0,15$ & $-0,43$ & 0,16 & 0,06 & $-0,29$ & $-0,11$ \\
\hline Assu & Alto R. & 1,25 & 40,80 & $-0,36$ & 0,01 & 0,84 & 0,29 \\
\hline Alto R. & Alto R. & 2,17 & 52,36 & 1,39 & 0,09 & 2,53 & 1,04 \\
\hline Alto R. & Mossoró & $-0,91$ & $-14,07$ & 0,64 & 0,00 & $-0,41$ & 0,03 \\
\hline Alto R. & Baraúna & $-0,90$ & $-0,53$ & 0,00 & 0,00 & $-0,13$ & 0,31 \\
\hline Alto R. & Assu & 1,19 & 50,57 & $-0,34$ & 0,02 & 0,60 & 0,27 \\
\hline Média & Mossoró & 0,49 & 30,72 & 2,76 & 0,01 & 0,27 & 0,34 \\
\hline Média & Baraúna & 0,24 & 0,72 & 1,38 & 0,09 & 1,17 & 0,63 \\
\hline Média & Assu & 1,26 & 81,91 & 1,06 & 0,13 & 0,88 & 0,49 \\
\hline Média & Alto R. & 1,16 & 32,87 & 0,5 & 0,03 & 1,35 & 0,58 \\
\hline Média & Média & 0,88 & 33,68 & 1,33 & 0,07 & 1,11 & 0,59 \\
\hline
\end{tabular}

$\mathrm{A}_{\mathrm{i}}$ : ambiente de seleção; $\mathrm{A}_{\mathrm{j}}$ : ambiente de resposta; PROD: produtividade $\left(\mathrm{t}\right.$ ha $\left.{ }^{-1}\right)$; PMF: peso médio do fruto $(\mathrm{g})$; PCI: proporção da cavidade interna (\%); EP: espessura da polpa (cm); FP: firmeza da polpa (N); SS: sólidos solúveis (\%); Alto R.: Alto do Rodrigues. 
possui grande extensão, não há viabilidade em selecionar um material para cada local de avaliação.

A seleção realizada na média dos ambientes com resposta esperada em ambientes individuais proporcionou ganhos positivos e mais próximos dos ganhos diretos verificados na tabela 3 . Com efeito, a seleção com base no comportamento médio das famílias nos quatro ambientes de seleção evidencia-se como uma alternativa para contornar a interação genótipos por ambientes (Tabela 3). Avaliando progênies de feijoeiro comum, ABREU et al. (1992) e TAKEDA et al. (1993) também observaram que a seleção com base na média dos ambientes reduz o efeito da interação sobre o ganho com a seleção.

Pelos resultados dos ganhos com a seleção, recomenda-se que as avaliações sejam realizadas em locais discrepantes e que a seleção com base na média desses locais é a mais recomendada. Além disso, quando a avaliação é feita em apenas um ambiente, recomenda-se não utilizar uma alta intensidade de seleção, pois as estimativas dos componentes de variância estão superestimadas pela interação genótipos por ambientes.

\section{CONCLUSÃO}

A interação famílias $\mathrm{x}$ ambientes é elevada $\mathrm{e}$ composta principalmente pela sua natureza complexa para todas as características avaliadas. As estimativas de coeficiente de variação genética e variância genética entre famílias em um ambiente são superestimadas pelo componente da interação genótipos $\mathrm{x}$ ambientes, sendo necessárias avaliações em mais de um ambiente. A seleção com base no comportamento médio das famílias proporciona maiores ganhos com a seleção em relação àqueles obtidos com base na seleção no ambiente individual.

\section{REFERÊNCIAS}

ABREU, A.F.B. et al. Effect of genotype $\mathrm{x}$ environment interaction on estimation of genetic and phenotypic parameters of common beans. Revista Brasileira de Genética, v.13, n.1, p.75-82, 1992.

CRUZ, C.D.; CASTOLDI, F.L. Decomposição da interação genótipos $\mathrm{x}$ ambientes em partes simples e complexa. Revista Ceres, v.38, n.219, p.422-430, 1991.

CRUZ, C.D. et al. Modelos biométricos aplicados ao melhoramento genético. Viçosa: UFV, 2004. 480p.

CRUZ, C.D. Programa GENES: biometria. Viçosa: UFV, 2008. 278p.

FALCONER, D.S.; MACKAY, T.F.C. Introduction to quantitative genetics. 4.ed. London: Longman, 1996. 464p. FERREIRA, D.F. et al. Statistical models in agriculture: biometrical methods for evaluating phenotypic stability in plant breeding. Cerne, v.12, n.4, p.378-388, 2006. Disponível em: $<\mathrm{ht} \mathrm{tp}: / / \mathrm{ww}$ w.d c f.ufla.br/cerne/artigos/ v12_n4_artigo\%2009.pdf>. Acesso em: 09 set. 2010.

FREITAS, J.G. et al. Interação entre genótipo e ambiente em híbridos de melão Amarelo no Nordeste do Brasil. Revista Ciência Agronômica, v.38, n.2, p.176-181, 2007. Disponível em: <http://www.ccarevista.ufc.br/seer/index.php/ccarevista/ article/viewFile/132/127>. Acesso em: 09 set. 2010.

GURGEL, F.L. et al. Indicação de híbridos de melão para o Rio Grande do Norte. Revista Ceres, v.52, n.299, p.115-123, 2005. Disponível em: <http://www.ceres.ufv.br/CERES/revistas/ V52N299P01005.pdf>. Acesso em: 09 set. 2010.

KARCHI, Z. Development of melon culture and breeding in Israel. Acta Horticulturae, v.510, p.13-17, 2000. (Proceedings of Eucarpia Meeting on Cucurbit Genetics and Breeding, 7.). Disponível em: <http://www.actahort.org/books/ 510/510_1.htm>. Acesso em: 09 set. 2010.

LIMA, L.L. et al. Coeficientes de variação de algumas características do meloeiro: uma proposta de classificação. Horticultura Brasileira, v.22, n.1, p.14-17, 2004. Disponível em: <http://www.scielo.br/pdf/hb/v22n1/ a03v22n1.pdf $>$. Acesso em: 09 set. 2010. doi: 10.1590/S010205362004000100003 .

NUNES, G.H.S. et al. Implicações da interação genótipos $x$ ambientes na seleção de clones de eucalipto. Cerne, v.8, n.1, p.49-58, 2002. Disponível em: <http://www.dcf.ufla.br/cerne/ artigos/13-02-20092115v8_n1_artigo\%2005.pdf>. Acesso em: 09 set. 2010

NUNES, G.H.S. et al. Aspectos produtivos e de qualidade de híbridos de melão cultivados no Agropolo Mossoró-Assu. Horticultura Brasileira, v.22, n.4, p. 744-747, 2004. Disponível em: <http://www.scielo.br/pdf/hb/v22n4/23187.pdf >. Acesso em: 09 set. 2010 doi: 10.1590/S010205362004000400015 .

NUNES, G.H.S. et al. Desempenho de híbridos do grupo inodorus em Mossoró. Horticultura Brasileira, v.23, n.1, p.90-94, 2005. Disponível em: <http://www.scielo.br/pdf/hb/v23n1/ a19v23n1.pdf $>$. Acesso em: 09 set. 2010 . doi: 10.1590/S010205362005000100019 .

NUNES, G.H.S. et al. Estabilidade fenotípica de híbridos de melão amarelo avaliados no Pólo agrícola Mossoró-Assu. Pesquisa Agropecuária Brasileira, v.41, n.9, p.1369-1376, 2006. Disponível em: <http://www.scielo.br/pdf/pab/v41n9/ a04v41n9.pdf>. Acesso em: 09 set. 2010. doi: 10.1590/S0100204X2006000900004.

SALES JÚNIOR, R. et al. Qualidade do melão exportado pelo porto de Natal-RN. Ciência Rural, v.36, n.1, p.286-289, 2006. Disponível em: <http://www.scielo.br/pdf/cr/v36n1/ a45v36n1.pdf $>$. Acesso em: 09 set. 2010. doi: 10.1590/S010384782006000100045 .

SANTOS JÚNIOR, J.J. Aspectos produtivos e de qualidade de híbridos de melões cultivados no Agropolo MossoróAssu (RN). 2002. 59f. Dissertação (Mestrado em Fitotecnia), Escola Superior de Agricultura de Mossoró-ESAM.

TAKEDA, C. et al. Evaluation of lines of cross a between ESAL 501 x A 354. Revista Brasileira de Genética, v.14, n.1, p.91-93, 1993. 